\title{
CIDADANIA E AÇÃO SOCIAL: CONTRIBUIÇÕES A PARTIR DA CATEGORIA "FORMAÇÃO"
}

Nilton Bueno Fischer*

SÍNTESE - Neste artigo analisamos uma experência, no campo da assistência social, desenvolvida na última década em Porto Alegre, a partir da contribuição da categoria formação. Enfatizamos a importância das atividades geradoras de renda por mulheres papeleiras junto aos galpões de reciclagem. A compreensão dessa prática social também envolve um processo formativo que incide também nos agentes de mediação bem como no conjunto da população.
ABSTRACT - In this article we analyze an experience, based on the "formation" category, developed in the social service field, which occurred in the city of Porto Alegre in the last decade. We emphasize aspects of income generation that women get from their work at plants for recycling. This social activity also contributes to a formation process in the side of the mediaton agents as well to the population as a whole.

\section{Introdução}

Através de uma prática social construída, nos últimos dez anos, no espaço urbano de Porto Alegre e pelo estudo mais detalhado dos seus elementos constitutivos, é possivel ampliar-se a compreensão do processo mais global de formação nela existente.

Na confluência de duas instâncias políticas, geradas isoladamente uma da outra, se inicia uma experiência inovadora. De um lado, as políticas públicas e os debates partidários, de outro, ações de assistência social e educação popular. Nas periferias urbanas, resultante de um longo aprendizado, interno às comunidades eclesiais de base (CEBS), a vocação do trabalho junto aos excluídos se transforma num projeto que vai alem da organização política, da reivindicação e das preces: inclui-se uma atividade nova, que contempla as anteriores e, simultaneamente, acrescenta ações de geração de renda. As novas formas de participação, na cena política, são renovadas pela proposta colocada em prática, através da administração popular, do orçamento participativo como forma concreta do cidadão incidir

Professor do Programa de Pós-Graduação em Educação da UFRGS. Linha de Pesquisa: Educação e Classes Populares. Pesquisador CNPq.

\begin{tabular}{|l|l|l|l|l|l|}
\hline VERITAS & Porto Alegre & v. 42 & $\mathrm{n}^{\mathbf{0}} 2$ & Junho 1997 & p. 283-290 \\
\hline
\end{tabular}


mais diretamente nos destinos dos recursos arrecadados pelo município de Porto Alegre.

Dentro dessa política global, buscando superar abordagens paternalistas, se situa uma ação mais diretamente relacionada com as classes populares: os galpões de reciclagem. Organizados em torno das CEBS, com apoio do poder público municipal através do Departamento de Limpeza Urbana (DMLU), se transformam em centros de destino da coleta seletiva, derivada do lixo seco urbano doméstico vindo a tornar-se fonte de renda de mulheres papeleiras. Nosso argumento, em torno dessa dinâmica vivida por alguns setores da população de Porto Alegre, se dirige aos saberes, por ela introduzidos, e que ainda não foram compreendidos pelo conjunto da população porto-alegrense, em suas dimensões mais abrangentes. É essa lacuna que desejamos completar a partir daquilo que esperamos se tornar um saber adquirido como responsabilidade de cidadania de todos.

As dimensões "mais abrangentes" do processo de formação, presente nessa prática social, se estruturam no encontro dos agentes - (formadores, gestores e formandos) num espaço informal (os galpões situados na periferia da cidade). Esse local é, ao mesmo tempo, permeado por outros espaços da cidade (residências, lojas, escritórios, escolas, igrejas e ruas) por onde os caminhões da coleta seletiva percorrem. Ou seja, os diversos espaços da cidade se fazem representar nos galpões, de maneira física/material, pela matéria-prima lixo urbano/seco.

Através da noção de formação econômico-social, presente na obra de Marx, interpretada por Lefebvre e comentada por José de Souza Martins é que fazemos a conexão com a categoria formação em seu sentido espacial e temporal. Mesmo com o risco que tal aproximação pode abarcar, entendemos ser indispensável a compreensão da existência de populações em situação de exclusão, como é o caso das mulheres papeleiras, dentro da perspectiva do desenvolvimento desigual, do "desencontro entre o econômico e o social na sociedade capitalista [...] o econômico anuncia possibilidades que a sociedade não realiza ou realiza com atraso". Martins, nessa mesma obra, ao interpretar as conseqüências desse descompasso, segue argumentando no sentido que a pobreza seria o resultado desse descompasso entre o econômico e o social: "a pobreza é pobreza de realização de possibilidades criadas pelo próprio homem para sua libertação das carências que o colocam aquém do possivel". O que adaptamos ao nosso argumento é trazer a categoria formação precedida de sua noção de processo histórico e entendermos assim como as ações de assistência social, constituídas em torno do trabalho das mulheres papeleiras, como sendo uma tentativa de superação dessa desigualdade (entre o econômico e o social).

Tendo isso em mente é que buscamos apoio em concepções de formação que superem, sem negar, a exclusividade da instância prática do saber-fazer para uma compreensão que inclua também as possibilidades de realização humana do homem. Desaulniers, apoiada em Tanguy, se reporta ao conceito de formação empregado por Empson: "Empson assinala que ultimamente o termo formação se refere não somente ao que diz respeito às grandes organizações como o Estado, Igreja, Forças Armadas, escola, empresa, mas também aos movimentos familiares, 
de jovens, grupos de lazer, Tc... Ou seja, não é mais só “a questão do trabalho, da produção e do poder que está em causa, mas o conjunto da vida, da totalidade das relações humanas".

A seguir apresento, de forma sintética, (procurando combinar tempos e espaços, dentro dos últimos dez anos) reflexões produzidas a partir do vivido pelos agentes de formação (mulheres papeleiras, assessores de educação popular, esferas do poder público municipal e agentes econômicos diversos). A tentativa é de desvelar uma espécie de currículo invisível existente no processo de classificação e reciclagem do lixo feito pelas mulheres papeleiras.

\section{Formação: saberes novos e conhecidos}

Uma prática social como o ato de consumir diariamente pressupõe ao comprador, além dos ganhos possiveis para atender suas necessidades, um conhecimento do que representam as modificações introduzidas dentro do processo produtivo visibilizado pelas embalagens das mercadorias. Independentemente de qualquer destino dos bens, tanto para alimentação como para o próprio vestuário, houve uma sensivel mudança na forma como estão acondicionados para a venda. Trata-se de modificação decisiva, especialmente na indústria de alimentos, pois as embalagens não são feitas somente para a sedução ao comprador (marketing) bem como para a sua conservação por mais tempo que a perecibilidade natural dos mesmos contem. Não precisaríamos relatar a diversidade dessas formas de acondicionamento pela sua especificidade técnica, mas certamente todos sabem que não sairão de uma loja ou supermercado sem sacolas de papel, plástico ou mesmo caixas de papelão. As tradicionais embalagens como a lata e o vidro tiveram também seu crescimento na proporção que também a indústria química de conservantes aumentou o tempo de duração dos produtos alimenticios.

Há, sem dúvidas, um novo saber instituído nessa prática cotidiana. O seguinte passo, para entender o destino dessa matéria-prima, ainda não superou o ato de usar algumas embalagens para guardar algo em casa ou fazer coleções como as latinhas de cerveja. A lacuna que anunciávamos anteriormente se situa nessa etapa: o cidadão, no ato de consumir, começa a identificar mudanças que envolvem os produtos naturalmente componentes de sua vida diária. Os caminhos hoje são outros pois o armazém, o açougue, por exemplo, começam a ser substituídos por novos locais, com novas formas de apresentação desses produtos. Há ausência de uma indagação a respeito do que envolve esse novo cenário, quer em termos de consumo de natureza pelas embalagens quer na ação predatória sobre a natureza provocada pela refrigeração dos produtos e dos próprios locais de venda.

A partir dos anos 60 , dentro do cenário dos movimentos sociais, a temática da ecologia se impõe como uma prática política para além das estruturas clássicas da representação política. O consumidor das embalagens se vê cobrado daquilo que não imaginava: os papéis e papelões que acondicionavam os produtos escolhidos para a sua sobrevivência, ou mesmo para qualificar o presente a ser dado, tinham uma relação direta com a devastação ambiental: para " $x$ " toneladas de papel significavam "y" árvores derrubadas. Saberes em relação começam a se manifestar: as enchentes tinham a ver com as margens dos rios cujas árvores foram derruba- 
das; o calor fora de época assim como os degelos estavam vinculadas com a diminuição da camada de ozônio que por sua vez era provocada pela combustão de gases de veículos automotores. Experiências cotidianas de produção de um saber que inquieta as possibilidades de qualidade de vida do ser humano são inúmeras mas em sua quase grande maioria carregam uma visão centrada nos possíveis prejuizos que causariam quase exclusivamente para os seres humanos. A característica antropocêntrica se manifesta claramente no tipo de análise, preocupação e mesmo em alguma ações e políticas a respeito do meio-ambiente.

Um outro saber começa a se instituir de forma reativa a esse tipo de conhecimento. O capital não se conforma com as denúncias da lógica predatória presente na produção econômica, mesmo sendo na inđustria de transformação como na agricultura e na agropecuária. O cidadão começa a encontrar, nas mesmas embalagens bonitas que envolvem os diversos produtos que adquire, alguns novos elementos de informação que dizem respeito ao controle de qualidade sobre 0 meio-ambiente. A lógica presente nesses produtos demonstra ainda uma forma de conhecimento que inclui mito mais elementos para "defesa" de uma forma de produção do que denúncia. A defesa se estruturaria pela argumentação com referenciais de pesquisa, com dados objetivos e científicos enquanto que a denúncia estaria ainda impregnada de subjetividade, emoção e/ou com objetivos políticos.

Esse saber se produz de forma permanente e insidiosa. As doses vem sendo dadas para o cidadão de maneira continua através dos mais diversos veículos de comunicação, independentemente de sua circulação ser do tipo jornal diário ou de um periódico científico restrito ao mundo acadêmico. A visão de homem e de sociedade, bem como do que representa conhecimento com status científico se desdobra de uma forma quase natural por cima de todos nós. Autores como Gramsci, ao proporem o entendimento sobre o significado de senso comum fazem a conexão sobre essas formas de conhecimento como representativas de mecanismos sustentadores de projetos políticos conservadores. Não se trata de um senso comum, com características imobilistas, de propriedade de uma classe social ou outra. Ao perpassar, transversalmente, por dentro de todos os territórios nos quais as pessoas vivem seu dia-a-dia, essa relação com a natureza, centrada no homem significa a sua propriedade, seu poder de subjugação. Estamos diante de um processo de formação de cidadãos conformistas com o principio gerador de oportunizar o bem estar para todos humanos com custos, quase irreversiveis, sobre os outros seres vivos.

A esse respeito Brandão nos instiga com uma reflexão muito pertinente ao que estamos discutindo. Propõe ele: "trazer o mundo da natureza ao palco da subjetividade. Alargar o lugar social do diálogo até o ponto em que outros seres, dotados de outras sensibilidades e, por certo, de outras disposições à comunicação, possam participar de uma mesma e muito diferenciada rede de comunicações conosco, ainda que não necessariamente sempre através de nós. Assim, a natureza e seus seres individuais, apropriados até aqui de acordo com os nossos interesses, devem ser libertados de serem considerados como uma dimensão outra da existência - o que não significa negar a alteridade de suas diferenças - caracterizada por uma passividade essencial e pressupostos, sobre a qual é então possivel 
o pleno exercício do domínio humano por meio do trabalho técrico regido pela utilidade social."

\section{Formação: saberes novos mas ainda desconhecidos}

As primeiras relações, feitas pelos homens a respeito de seu gesto de consumir para além dessa função utilitarista, começam a perturbar uma lógica presente em sua forma de se relacionar com o mundo ao seu redor. Não bastam as multas por queimadas, poluições, desmatamentos, erosões e até a taxa de lixo urbano para sinalizarem alertas na consciência dos homens. Há algo novo sendo produzido na relação homem/natureza.

Um saber novo, mas conhecido, é aquele que permite um conhecimento entre o que é reaproveitado da produção industrial como novo insumo que se introduz na cadeia produtiva. No setor de móveis, por exemplo, estamos presenciando o uso dos resíduos de madeira para se transformarem numa pasta, chamada aglomerado, que após um sistema de prensagem se transforma numa chapa reutilizável na fabricação de móveis. As madeiras nobres, já quase inexistentes, aparentam existir através do uso das lâminas coladas em chapas com misturas de restos de outros tipos de madeira provenientes de árvores de crescimento rápido como o próprio pinus ellioti.

Estranha tomada de consciência é essa que os homens começam a demonstrar. As denúncias feitas pelos ambientalistas, em torno da diminuição da qualidade de vida no planeta, que falam de rios, árvores e mesmo das mudanças de temperatura (aquecimento) aos poucos vão formando um conhecimento da relação homem-natureza que sinaliza para uma perspectiva de fora para dentro. As esperadas ações humanas, sintonizadas com esse conhecimento, deveriam resultar em práticas concretas e imediatas a serem instituídas no dia-a-dia das pessoas. Entretanto isso está ainda distante de acontecer como forma "natural" por parte das pessoas. Talvez resida aí ainda o impasse para qualificarem os seus gestos: desconhecem ou não relacionam o imediato, o vivido, o presente com significância de futuro, de relações de totalidade.

Consideramos um conhecimento ainda pouco apropriado pelo conjunto da população aquele diretamente relacionado com a internalidade do que ocorre no cotidiano das unidades produtivas onde trabalham as mulheres papeleiras. Se fossemos acompanhar a dinâmica do caminho clássico percorrido pela matériaprima lixo seletivo e perguntássemos ao cidadão que etapas são essas talvez chegássemos a conclusão que, no máximo, ele saberia que o destino do lixo são os galpões situados nos diversos bairos da cidade. Talvez ele fosse manifestar ainda algum entendimento a respeito dos possiveis ganhos que mulheres obteriam a partir da venda desse material. As etapas seguintes estariam somente no terreno de hipóteses.

São os processos extremamente complexos e, ao mesmo tempo, riquíssimos de esperança, que tentaremos apresentar ao leitor para a sua reflexão. 


\section{Formação: agentes no espaço da periferia urbana}

A migração, para os grandes centros por parte de pessoas que moravam e trabalhavam no campo, combinada com a continua expulsão de moradores da cidade, para as suas periferias, evidencia as características de uma formação social cujo crescimento econômico privilegia uma lógica de acumulação descompassada de seus aspectos sociais. As populações, nessas situações, se constituem mais como números do que seres humanos dignos. Os diversos componentes desse território em constante mutação através das alterações em suas habitações, vias de acesso e presença de algumas políticas públicas, vem a desafiar àqueles que se pensam como agentes de mediação através de práticas de objetivos emancipatórios. Encontramos aí os partidos políticos, associações de moradores, postos de saúde, igrejas e mesmo o Estado, o poder público.

O cenário mutável se apresenta ao morador da metrópole como sendo o local da insegurança. Os deslizamentos de terra, as cenas de crimes e de tráfico de drogas, os assaltos, a pobreza presente nos equipamentos públicos vão construindo uma forma de conhecimento na qual está privilegiado a "não-vida". Não seria novidade alguma que junto aos restos de uma qualidade de vida humana fossem agregados os restos, as sobras de uma outra parte da população. Os bens consumidos por uma parte mais privilegiada da população se transformariam num mecanismo indireto de comunicação com os setores da população com características de exclusão a esses mesmos bens.

Ao residirem (?) nas margens das cidades os subcidadãos serviriam como um imenso laboratório de experimentação social. O cenário passa a ser um local no qual atores entram e saem na medida em que se esgotam os tempos de seus projetos vindos de fora. As pesquisas emancipatórias terminam pelo prazo de seus relatórios, as assessorias das igrejas se esgotam quando mudam os pastores, padres e religiosos, os representantes do poder publicam se afastam quando os seus mandatos terminaram. As pessoas moradoras continuam vivendo e a complexidade do cenário fica aumentada pela diversidade de orientações dos mais diferentes projetos em circulação. Através de uma preocupação firme com parte de uma população que trabalhava junto aos lixões da cidade, alguns educadores populares, originários de uma sólida prática junto aos setores populares, resolveram enfrentar esse desafio: tentar garantir a continuidade desses projetos.

Entre a intencionalidade de propostas de ação que pudessem garantir alguma continuidade e as práticas anteriores de assessoria, emerge a possibilidade da geração de renda através de uma atividade econômica até então realizada de forma individual, no espaço das vias públicas e até mesmo um tanto esporádica: 0 reaproveitamento do lixo urbano seco. Iniciada através dos restos de embalagens usadas no comércio (especialmente o papelão) e de papeis usados (especialmente o jornal) e de coleta feita pelos carrinheiros ao longo das ruas, a atividade é agora transformada em seus aspectos organizacionais, através de grupos de trabalho, dentro de um local fixo e incluindo outras matérias-primas como o plástico e o vidro. Essa radical mudança foi sendo produzida através de uma pedagogia freireana na qual se tentava entender o que a trajetória dos carrinheiros podia colaborar nessa nova forma de trabalho. 
A característica de continuidade se constituia pelo conhecimento mais aprofundado das relações existentes no espaço onde se processa uma forma de reciclagem: nos fundos das casas das famílias. $O$ enraizamento de uma atividade produtiva, no espaço da convivência familiar, mesmo que nos fundos do pátio e junto com animais, especialmente porcos, promove a presença da mulher como trabalhadora. A transferência para um local coletivo, menos insalubre e com alguns equipamentos ainda rudes, oportunizou aos educadores populares, a compreensão da presença feminina como condição básica para o funcionamento dessa nova modalidade de atividade produtiva: trabalhar com a matéria-prima lixo seco, urbano e doméstico, como fonte geradora de ganhos econômicos. Uma reflexão se faz necessária desse conhecimento adquirido: papéis diferenciados, entre homem e mulher, de acordo com as características das matérias-primas e sua localização dentro do espaço urbano. Homens, carrinheiros, circulando pela cidade encontram seus fornecedores, de papel e papelão, junto ao circuito das empresas comerciais. Eles podem ter o tempo de quase um dia inteiro fora de casa, gerando renda e/ou socializando suas vidas em grupos de rua. A mulher, pode acompanhar a vida familiar dos demais, sejam eles filhos, pais e outros parentes e ter um tempo para a produção em local próximo de sua moradia. Aprendizagens ocorreram tal qual um curso de formação profissional (qualificação) no qual a diferenciação entre uma atividade semelhante ao garimpo (que existe nos lixões ou mesmo no fundo de quintal) e uma atividade mais seqüencial, organizada e menos aleatória. Os registros dessas transformações ficaram na instância dos assessores e ainda há muito que se resgatar a partir dos depoimentos das mulheres que foram as pioneiras nesse tipo de trabalho. Uma categoria que se produziu nessa passagem (da saída do fundo de quintal para os galpões) aliada a descoberta da mulher como produtora e sujeito nessa atividade, sem dúvida parece ser a categoria continuidade.

A categoria continuidade demanda a garantia no aperfeiçoamento do processo de trabalho e, ao mesmo tempo, como forma decisiva, a presença qualificada das assessorias em prontidão para essas novas exigências. A isso denominamos como processo de formação "mão dupla", ou conforme nos sinaliza Martins (1989) na diferenciação entre objeto e objetivo, significando com isso que a imersão nos projetos de geração de renda junto com as mulheres papeleiras também provocou mudanças na maneira de pensar dos agentes de mediação.

A formação, presente no cenário dos galpões, junto às mulheres papeleiras, se constitui numa prática social que se relaciona com outros agentes como o poder público, as empresas, as assessorias das universidades, as igrejas, etc. Em torno dessa característica básica que é, geração de renda a partir do lixo, a continuidade se torna uma exigência para a garantia de sua viabilidade.

A política pública, estabelecida por um perfil de administração como tem sido a prefeitura municipal de Porto Alegre, deve se tornar aos poucos uma propriedade da sociedade, de tal maneira que possa se aperfeiçoar constantemente e de forma cada vez mais independente de quem responde pelo poder municipal. Para isso se torna necessária a contribuição dos outros agentes formadores que estão atuando junto nos galpões. Esses agentes tem características próprias dependendo dos interesses que representam. Um exemplo, para a garantia de continuidade, pode 
ser a presença de representantes do mercado comprador dos produtos gerados nos galpões. Uma vez estabelecida uma rede de compra e venda, incluindo-se aí a qualidade dos produtos e estabelecidas as condições de preço, prazos e quantidades, é previsivel que esse setor demonstre a sua importância no sentido de garantir o fornecimento da matéria prima para os diversos outros compradores. A alternativa de se ter uma central de vendas, para que os galpões não percam dinheiro pela oferta fragmentada de seus produtos, bem como uma política de estoques, e até mesmo de introdução de novas tecnologias dentro das unidades produtivas, são possibilidades formativas, quase ilimitadas que a instância econômica ajuda a produzir e que ainda não fazem parte do conhecimento da maioria da população.

Os formadores mais clássicos, como aqueles oriundos da educação popular, fazem do trabalho com o lixo, como forma de conhecer as múltiplas conexões que existem na sociedade contemporânea. A qualificação, presente na formação passa a se constituir como desafio para esses agentes formadores, pois de uma certa forma descentra a ênfase nas denúncias para a compreensão da importância do processo de conhecimento nos ganhos salariais das mulheres, por exemplo.

\section{Formação: agenda cultural, um processo ainda incipiente}

Divisamos, para um futuro bem próximo, acréscimos nas atividades junto aos galpões, com uma perspectiva que poderia ser denominada de "uma agenda cultural" a qual representaria uma efetiva aproximação com os pressupostos que a categoria formação inclui como concepção: "[...]o conjunto da vida, da totalidade das relações humanas" (Empson, in Desaulniers).

As mulheres papeleiras, ao longo dos dez anos de sua experiência de se tornarem cidadãs (e não tuteladas pela benemerência das instituições e pelo Estado), tem oportunizado momentos nos quais essa agenda cultural se torna uma demanda tão ou mais importante que a econômica. A condição da mulher em processo de autonomização, material e politicamente, está instigando pessoas que circulam nos espaços onde essa formação está ocorrendo. Destacamos, nesse processo, a lenta mas firme determinação em incluir temáticas formadoras tais como: educação, sexualidade, concepção de vida.

Concluindo, poderíamos afirmar que o processo de formação presente nesta prática social, com mulheres papeleiras, é de tal intensidade que coloca-nos diante de um imenso campo de possibilidades profissionais. A condição básịca para enfrentar esse desafio está na procura de abordagens teórico-metodológicas que contribuam para um conhecimento cada vez mais aprofundado e sensivel para a superação de situações de exclusão social.

\section{Referências bibliográficas}

BRANDÃO, Carlos Rodrigues. Somos as águas puras. Campinas, SP: Papirus, 1994.

DESAULNIERS, Julieta Beatriz Ramos. Formação, ou qualificação, ou competência... in: Revista Veri-

tas. v. 38, n. 149, março 1993, Porto Alegre: RS. pp 95-100.

MARTINS, José de Souza. Caminhada no chão da noite. São Paulo, SP: Hucitec, 1989.

MARTINS, José de Souza (org.). Henni Lefebvre e o retorno à dialética. São Paulo, SP: Hucitec, 1996. 